Goldschmidt 2021 Abstract

https://doi.org/10.7185/gold2021.8065

\section{An Interactive Atlas of Geochemical Diagrams for Critical Metals}

\author{
EVGENIY BASTRAKOV ${ }^{1}$, JOËL BRUGGER ${ }^{2}$, JEFFREY \\ DICK $^{3}$, QIUSHI GUAN ${ }^{2}$, WEIHUA LIU ${ }^{4}$, YUAN MEI ${ }^{4}$ AND \\ ARTACHES MIGDISSOV ${ }^{5}$
}

${ }^{1}$ Geoscience Australia

${ }^{2}$ Monash University

${ }^{3}$ School of Geosciences and Info-Physics, Central South University

${ }^{4} \mathrm{CSIRO}$

${ }^{5}$ Los Alamos National Laboratory

Presenting Author: evgeniy.bastrakov@ga.gov.au

The accelerating pace of population growth, economic development and technological innovation drive increased demand for non-fuel mineral commodities vital for emerging and low-carbon technologies. Lists of relevant chemical elements, also considered critical to the economic and national security of the world's major and emerging economies (often dubbed "critical minerals") vary from country to country but commonly include REE, Ga, In, W, PGE, Co, Nb, Mg, Mo, Sb, Li, V, Ni, $\mathrm{Ta}, \mathrm{Te}, \mathrm{Cr}$ and $\mathrm{Mn}^{[1]}$.

Comprehensive thermodynamic datasets of aqueous species and minerals of critical elements underpin research activities on critical elements. The latter include improved understanding of the formation and processing of critical minerals achieved via geochemical modelling; mapping of critical mineral systems in terms of variables relevant to geological and environmental (e.g., temperature, pressure, concentrations of solution components); opening new greenfield areas for exploration for critical minerals achieved with insights from numerical modelling of mineral systems; and designing more efficient and greener mineral processing methods.

Currently, databases included in popular and readily available packages for geochemical modelling are fragmented at best. To address this issue, a concerted effort to (1) compile and evaluate available thermodynamic data and (2) cover the revealed gaps by targeted experimental studies is required. In recent years, traditional experimental studies are complemented by (3) $a b$ initio molecular dynamics simulations to predict aqueous speciation and thermodynamic properties of metal complexes.

Here we present a publicly available (by the date of this conference) curated dataset of critical metals' thermodynamic properties, with an initial focus on REE, Y, Co and W. The dataset is incorporated into GeoTPD, a package of interactive web applications based on CHNOSZ ${ }^{[2]}$. We will discuss the compiled data and on-the-fly generation of common geochemical diagrams such as redox- $\mathrm{pH}$, activity-activity, $\mathrm{T}-\mathrm{pH}$, fO2- $\mathrm{T}$ and solubility within a wide range of temperatures and pressures.

References:

1. https://www.ga.gov.au/about/projects/resources/criticalminerals (accessed 26 Feb 2021)

2. Dick (2019), Frontiers in Earth Science, 7, doi:10.3389/feart.2019.00180.
Figure 1: An example T-pH stability diagram for Y. The required data for aqueous $\mathrm{Y}$ species were calculated with the $a b$ initio thermodynamic integration method.

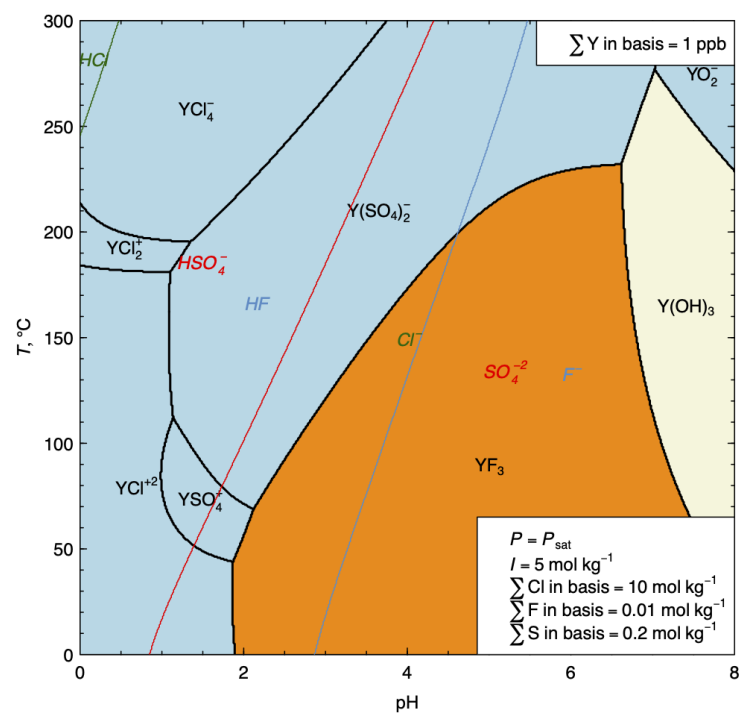

